\title{
Cost Management of a CFBC Boiler in a Thermal Power Plant
}

\author{
P V Narendra Kumar, Ch Chengaiah, G Kiran Kumar
}

\begin{abstract}
India, being the world's third most noteworthy power maker with all out exhibited purpose of containments of $344.69 \mathrm{GW}$, contributing $68 \%$ of thermal Capacity. Subsequently, Thermal power producing stations are basic. As an electrical architect, exceptional consideration ought to be taken to decrease coal utilization in Thermal power generating stations. In Thermal power producing stations, boilers utilized are Circulating Fluidized Bed Combustion (CFBC) and Atmospheric Fluidized Bed Combustion (AFBC). These boilers utilize bed material to keep up warmth in the boiler. 210MW and under $210 \mathrm{MW}$ generators in the Thermal power producing stations are utilizing CFBC boilers. After a nearby examination of thermal power stations, it is discovered that the bed material including over $5 \%$ of engaging parts are open in the bed material which is horrendous. This happens where magnetic separator at the bed material stacking point is missing or far off. From this time forward it is proposed to introduce a magnetic separator at the bed material stacking point. With this establishment of magnetic separator hardware, boiler efficiency can be reached out to $2.1 \%$ more, to keep up the required temperature and to maintain a strategic distance from boiler stoppages. An endeavor has been made to perceive the usage required presenting attractive separator and it has been discovered that the reward period is obliged to roughly 1 to 2 years if the engaging sections in the bed material are 5\%and 10\% respectively. The Proposed issue is endeavored with MATLAB condition and cost examination of thermal power plant is separated and existing synthesis information. The test outcomes displayed that the proposed framework gives an attainable game-plan gigantic theory saves and liberal for consistent assignments.
\end{abstract}

Index Terms: Imperativeness Situation, Types of boilers, bed material, Magnetic separator, capacity, compensation period, MATALB.

\section{INTRODUCTION}

As indicated by Central Electricity Office (CEO), in India, 144thermal plants radiated 8.5 crores huge amounts of fiery debris amid first 50\% of 2018-19. Notwithstanding, the introduced limit of thermal power producing plants as on August 2018 is 2, 18,330 MW, where $60 \%$ of the thermal power plants are just in running condition. Around the world, Fuel assets are diminishing quickly. Redesigns utilizing the most recent movements are continuing,

Revised Manuscript Received on August 20, 2019.

P V Narendra Kumar*, Department of Electrical \& Electronics Engineering, Sri Venkateswara University, Tirupati, INDIA.

Ch.Chengaiah, Department of Electrical \& Electronics Engineering, Sri Venkateswara University, Tirupati, INDIA.

G. Kiran Kumar, EEE, Sri Venkateswara University, Tirupati, India. diminishing the typical fuel assets. Be that as it may, if the fuel utilization is completely controlled, the polluting is in all probability going to be reached out to an incomprehensible measurement driving approach to manage dangerous events. As the interest creates, age in addition expands inciting more coal utilization. For improvement, fuel age plants and undertakings are the genuine foundations for temperature rise and sullying. To collect a Thermal Power Plant for Mega wattage of effect in the conditions of Andhra Pradesh and Telangana state, the cash required is roughly seven crores. To convey from thermal making Power plant, coal is utilized as a fuel. Precisely when coal is scorched, carbon dioxide, carbon monoxide, nitrogen oxide and sulfur oxides are evacuated. These gases obviously or in a backhanded way debase the encompassing zones and henceforth it is extraordinarily hard to live in and around the thermal plants. In the going with hundred years, the fuel assets will decreases significantly. The exhibited reaches of thermal power plants in India are appeared in table 1.

Table I: Installed Capacity of Thermal Power Plants

\begin{tabular}{|c|c|}
\hline \multicolumn{2}{|c|}{ Installed Capacity } \\
\hline Year & Generation Capacity $(M W)$ \\
\hline $2012-13$ & $1,30,000$ \\
\hline $2013-14$ & $1,45,000$ \\
\hline $2014-15$ & $1,65,000$ \\
\hline $2015-16$ & $1,85,000$ \\
\hline $2016-17$ & $1,92,000$ \\
\hline $2017-18$ & $1,93,000$ \\
\hline
\end{tabular}

As shown by the data given by NITI Aayog, constantly 2040, we have to fabricate 3,30,000 Megawatts purpose of restriction of warm power plants to manage the nation's advantage. To run these plants, it is evaluated to use 100 Crore gigantic proportions of coal. It means a greater national sullying. Along these lines it is required to eat up the coal in a controlled way. In the event that the coal is viably used in the plants, the exhausting of coal can be decreased there by reducing the contamination. This can be rehearsed by methods for deliberately picking quality bed material and mixing of coal. This work is in relationship with the choice of critical worth bed material construing the central focuses it offers by developing the eventual fate of evaporator and sparing a ton to the exchanger [1]. In a reliably making industrialization of make and making countries, electric power age through boilers of thermal power stations have acknowledged key occupation over a century. Coal, lignite, 
fuel oil, flammable gas and so on are a portion of the fills accessible as standard assets and these are being eaten up for steam age. begin in customary stoker finished, beat coal let go and what's more oil/gas let go boilers discharge contaminations like Sox, NOx, CO and so on dependably in altogether more noteworthy entireties which are perilous to human life[2]. This point of view has been drawing in more idea of governments and moreover individuals and the rule rotate is at present around time of steam with condition inviting game-plan of closure boilers. In the boiler, this material is sprinkled and it shapes a bed thickness of $500 \mathrm{~mm}$. if all else fails, the bed material ought not include over $5 \%$ of attractive material. In the event that a charming fragment in the bed material structure, the required temperature can't be kept up in the kettle, causing endless stoppages, stretching out utilization of coal to keep up demonstrated warm and decreased evaporator productivity [3]. Everything considered the evaporator capacity is $85 \%$ with a fate of 10 to 15 years. Flowing Fluidized Bed Combustion kettle offers important answer for decrease sick impacts of contamination. Notable focal points of this framework is that the fuel of various sorts/cause and quality can be signed with no issues at high level of effectiveness [4]. Contaminations, for example, Sulfur dioxide, Hydrogen Chloride, Hydrogen Fluoride discharged amidst begin are held in the powder with the assistance of Limestone dosing. Because of low devouring and created begin temperature; strategy of nitrogen oxide is generously diminished. Along these lines reduction of vaporous debasements made amidst devouring is developed by begin process itself, which is strength of this headway. Pipe gases cleaning structures, which are unavoidable in standard boilers, are unnecessary in CFBC framework and refraining from extra suitability difficulties [5]. The stationary fluidized bed finishing framework are the low hypothesis cost, clear and solid closure system and direct fuel arranging [6] when emerged from AFBC and it is coursing fluidized bed consummation structure which are high devouring productivity, high sulfur upkeep with low limestone use and lower NOx improvement helped by dealt with terminating. The CFBC advancement offers astoundingly solid procedures for steam age by exhausting an expansive variety of non-renewable power sources enough and joining the best of both settled and coursing liquid bed moves.

\subsection{Bed Material}

Notwithstanding the bed material is sand. Some part is lost in the intensity hot remains amidst the errand and this must be made-up. In coal terminated boilers, the cinder from the coal itself will be the cosmetics material. When terminating bio powers with low powder content sand is the bed material will be made up. For high Sulfur coals, this Limestone improvement to the bed material reduces SO2 discharges.

\subsection{Fluidized Bed}

At the base of the boiler there is a bed of inactive material. Bed is the place the coal or fuel spreads. Air supply is from under the bed at high weight. This lifts the bed material and the coal particles and keeps it in suspension. The coal burning happens in this suspended condition. This is the Fluidized bed. Special plan of the air spouts at the base of the bed permits wind current without stopping up. Essential air fans give the preheated Fluidizing air. Optional air fans give pre-warmed Combustion air. Spouts in the hotter dividers at different measurements dissipate the Combustion air in the furnace. CFBC uses squashed coal of 3 to $6 \mathrm{~mm}$ measure. This requires just a smasher not a pulverizer. From point of confinement compartments through Conveyer and feeders transport the coal to help chutes in the radiator. Startup is by oil burners in the radiator. Blasting debris gushes in the hotter expel the sediment from the base of the furnace. Boiler in the coal is burned is in a zone of high assembling of bed material (mineral issue) got from devouring of coal held by utilizing tornado/different techniques. This bed material is fluidized by crucial air (a touch of expending air).The high centralization of bed material close-by sorted out air supply guarantees that mass begin temperatures don't beat $950^{\circ} \mathrm{C}$ making it condition liberal (lesser creation of NOx) by means of using coal [7].It handles a strategy not proportional to pulverized Fuel where coal is set up to fine powder (like new born child powder) and finished. The centralization of super hot debris is destitute of coal powder (mineral issue) substance and fiery remains (mineral issue) oblige pipe gases out of the radiator. In CFBC radiator, this intensity hot junk (mineral issue) is kept utilizing a twister or close contraption and reused and therefore named as Circulating Fluidized Bed . AFBC kettle is less able than the CFBC boiler.In Thermal power generating stations, the sorts of boilers utilized are Circulating Fluidized Bed Combustion (CFBC) and Atmospheric Fluidized Bed Combustion (AFBC). These boilers use bed material to keep up warmth in the boiler. 210MW and under $210 \mathrm{MW}$ generators in the Thermal power creating stations will utilize CFBC boilers. In the evaporator, this material is sprinkled as bed material to layout a thickness of $500 \mathrm{~mm}$. everything considered, the kettle suitability is around $85 \%$ with a fate of 10 to 15 Years. On watching Thermal power making stations, it was seen that the bed material utilized includes charming sections of over $5 \%$ which is stunning.

\section{Problem Formulation}

Consider a Thermal Power Generating Station of four generators. Imply cutoff of Thermal Power Generating Station is $600 \mathrm{MW}$ and Maximum Capacity of every generator is $150 \mathrm{MW}$. The boilers utilized in this Thermal Power Generating Station are Circulating Fluidized Bed Combustion (CFBC) boilers. In the kettle, this material is sprinkled and it traces with a bed thickness of $500 \mathrm{~mm}$ to $600 \mathrm{~mm}$. Unending supply of the bed material, the equivalent is endeavored to discover its personality of being free from any sort of engaging fragments. If all else fails, the bed material ought not include over $5 \%$ of charming components. The official will check the bed material from each dispatch already allowing depleting it

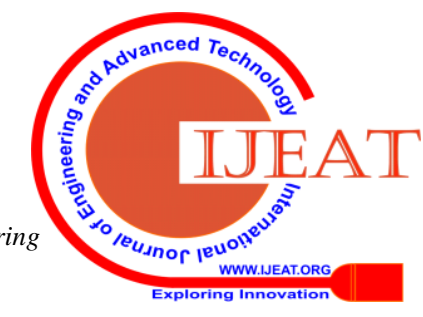


and appearing relative to the lab for finding the element of engaging parts in the bed material. Without charming separator at the cleansing site, the official is obliged to gather the examples of bed material sporadically and present the proportionate to the investigation office for finding the component of engaging portions in the bed material. The lab report is conveying that the alluring portions in the bed material are under $5 \%$ everything idea of it as is more basic than $5 \%$. This occurs as abstract models are gathered from the truck heap of material from various areas making the test result to change past required outcomes. On the off chance that an appealing portion in the bed material structures, as that point acceptable warmth can't be kept up in the boiler, developing the stoppages, and utilization of coal and particularly influencing the evaporator life. An intelligent examination composed on the fourth generator's kettle uncovered that the capacity of the evaporator was diminished to $83.50 \%$ from $85.60 \%$.Table. 2 underneath demonstrates the sorted out attributes and ensured estimations of the heat rate of a unit, and suitability of boiler.

Table II: Designed and Actual estimations of a Boiler

\begin{tabular}{|l|l|l|}
\hline \multicolumn{1}{|c|}{ Parameter } & \multicolumn{1}{|c|}{$\begin{array}{c}\text { Designed Values } \\
\text { Kcal/KWh }\end{array}$} & \multicolumn{1}{|c|}{$\begin{array}{c}\text { Actual Values } \\
\text { Kcal/KWh }\end{array}$} \\
\hline Turbine Heat Rate & 1985 & 2596 \\
\hline Boiler Efficiency & $85.60 \%$ & $83.50 \%$ \\
\hline Unit Heat Rate & 2277 & 3109 \\
\hline
\end{tabular}

\section{Proposed Method}

It is proposed to introduce a Magnetic Separator at the bed material stacking point. Here, the Generating station, every kettle expects 4 to 6 Tons of bed material every day making it to 16 to 20 Tons for four boilers. Everything thought reliably, around 450 to 600 Tons of bed material is required by four generators. Utilization of bed material by an evaporator relies on hotter execution and activity. The line graph of the proposed work is appeared in fig 1 .

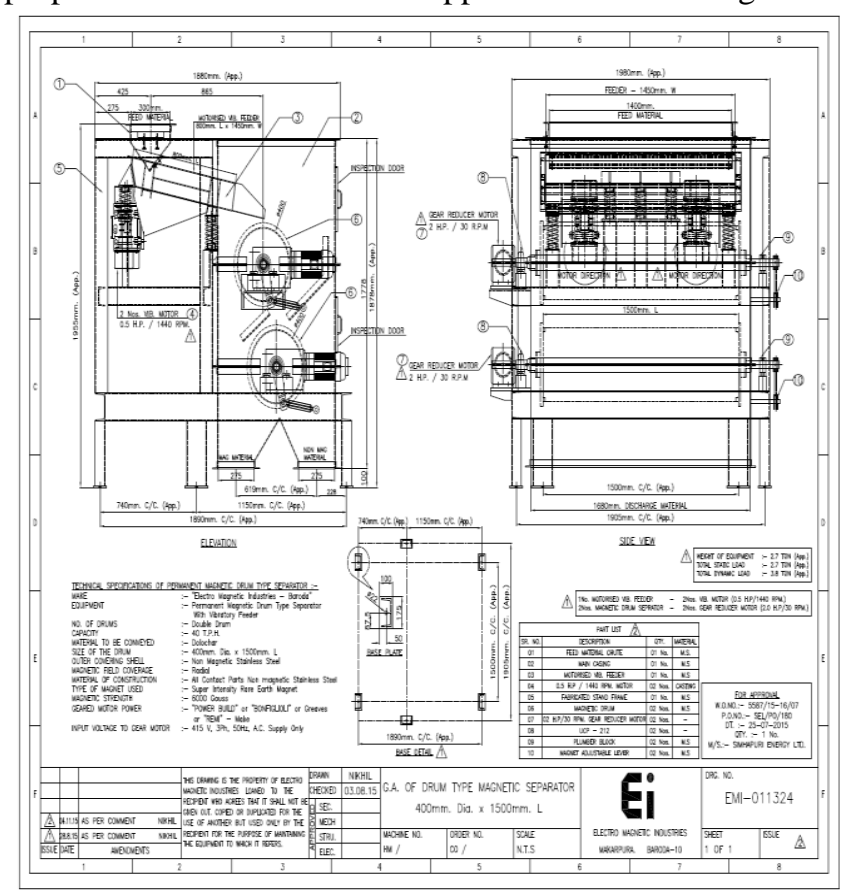

Fig.1: Line Diagram of Magnetic Separator.
The utilization of bed material for all encompassing length of august for fourth Generator in the Thermal Power Generating Station under investigation is appeared in Table III.

Table III: Consumption of Bed Material

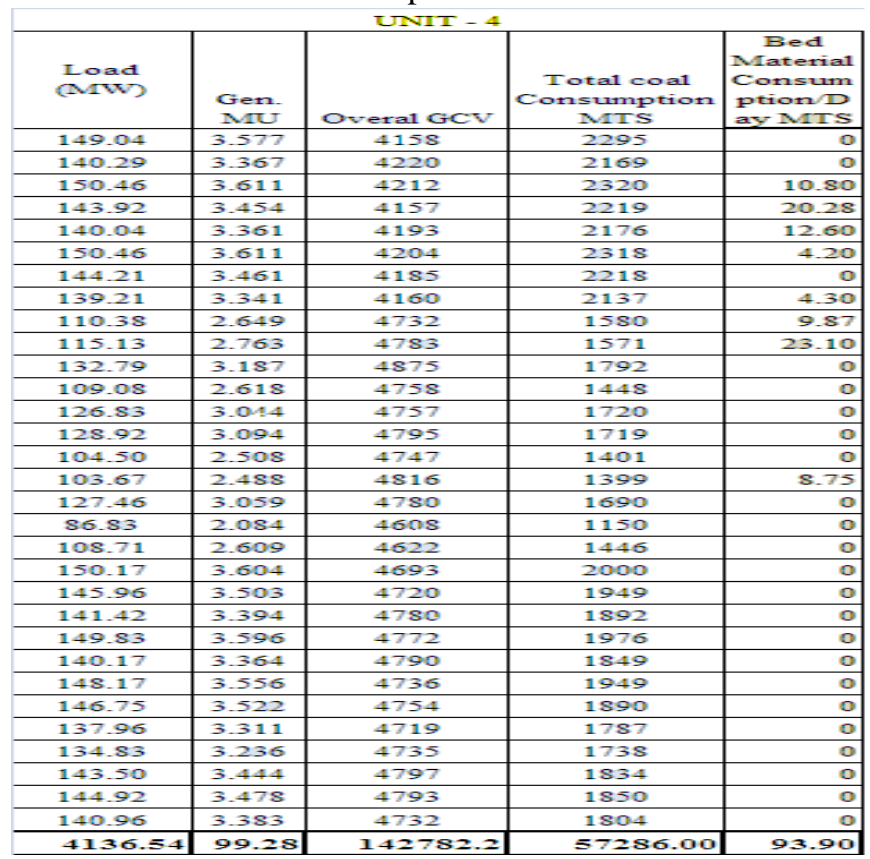

The unpretentious parts of built piece and size of the bed material is appeared in Table. 4 and Table. 5 separately.

Table IV: Chemical Composition of the Bed Material

\begin{tabular}{|l|l|}
\hline Item Description & \multicolumn{2}{|l|}{ Specification } \\
& Chemical Composition \\
\hline Refractory Bed Material & Alumina $30 \%-35 \%$ \\
(Below 1 mm) & Silica $55 \%-60 \%$ \\
Crushed Calcined & Ferric Acid < $3 \%$ \\
refractory bed material for & Bulk Density $1.0-1.1 \mathrm{gm} / \mathrm{cc}$ \\
boiler. & Iron $\quad 0.2 \%-0.3 \%$ \\
\hline
\end{tabular}

Table V: Chemical Composition of the Bed Material

\begin{tabular}{|l|l|}
\hline Size of the Bed Material & Specifications \\
\hline $1 \mathrm{~mm}$ to 850 microns & $75 \%-80 \%$ \\
\hline 850 microns to 500 microns & $15 \%-20 \%$ \\
\hline 500 microns & $<5 \%$ \\
\hline
\end{tabular}

The usage accomplished in raising an appealing separator is appeared in Table. 6

Table VI: Expenditure in raising a Magnetic Separator.

\begin{tabular}{|l|l|l|}
\hline S.No & Description & Cost (Rs.) \\
\hline 1. & Magnetic Separator & $15,40,925.00$ \\
\hline 2. & Material used for Structure & $3,28,707.00$ \\
\hline 3. & $\begin{array}{l}\text { Consumables used for } \\
\text { erection }\end{array}$ & $19,711.00$ \\
\hline 4. & Cost of Man Power involved & $2,91,755.00$ \\
\hline 5. & Operation \& Maintenance & $2,00,000.00$ \\
\hline Total: & $23,81,098.00$ \\
\hline Source: Simhapuri Thermal Power Station, AP
\end{tabular}

The expense of bed material is Rs.5000/ - per Ton. It is foreseen that 6000 Tons of bed 
material is required for the Thermal Power Generating Station. The Engineer, Department of Operation and Maintenance, will plan 1500 Tons of bed material for each quarter, making it to various occasions in a year i.e., 6000 Tons of bed material. As there is the equivalent engaging separator at the cleansing purpose behind bed material, the chief is obliged to gather the occasions of bed material erratically and present the practically identical to the lab for finding the element of appealing sections in the material. While the investigation center report display the appealing parts in the bed material as 5\% whereas on authentic testing the sections constantly found over $5 \%$ when the indistinguishable is strengthened to the kettle. plus, toward the end, the wastage in the bed material is found remaining between $5 \%$ to $10 \%$ expanding critical hardships.

Table VII: Cost of Wastage Bed Material

\begin{tabular}{|c|c|c|c|c|}
\hline S.NO & $\begin{array}{l}\text { Bed } \\
\text { Materia } \\
1 \\
\text { (Tons) }\end{array}$ & $\begin{array}{l}\% \text { of } \\
\text { Magneti } \\
\mathrm{c} \\
\text { elements }\end{array}$ & $\begin{array}{l}\text { Cost } \\
\text { (Rs) }\end{array}$ & $\begin{array}{l}\text { Pay Back } \\
\text { Period } \\
\text { (Months) }\end{array}$ \\
\hline \multirow{3}{*}{1} & \multirow{3}{*}{5840} & 5 & $\begin{array}{l}14,60,00 \\
0\end{array}$ & 20 \\
\hline & & 7.5 & $\begin{array}{l}21,90,00 \\
0\end{array}$ & 14 \\
\hline & & 10 & $\begin{array}{l}29,20,00 \\
0\end{array}$ & 10 \\
\hline \multirow{3}{*}{2} & \multirow{3}{*}{6570} & 5 & $\begin{array}{l}16,42,50 \\
0\end{array}$ & 18 \\
\hline & & 7.5 & $\begin{array}{l}24,63,75 \\
0\end{array}$ & 12 \\
\hline & & 10 & $\begin{array}{l}32,85,00 \\
0\end{array}$ & 9 \\
\hline \multirow{3}{*}{3} & \multirow{3}{*}{7300} & 5 & $\begin{array}{l}18,25,00 \\
0\end{array}$ & 16 \\
\hline & & 7.5 & $\begin{array}{l}27,37,50 \\
0\end{array}$ & 11 \\
\hline & & 10 & $\begin{array}{l}36,50,00 \\
0\end{array}$ & 8 \\
\hline
\end{tabular}

By ethicalness of the engaging parts in the bed material, adequate heat can't be kept up in the boiler, causing expanded stoppages and by developing the utilization of coal and diminishing the life of the kettle.

\section{RESULTS AND DISCUSSIONS}

Presently multi day, sub basic power stations are running at its $40 \%$ efficiency. Efficiency can be figured as Efficiency $860 /$ Heat Rate. It implies if whole substance vitality which is available in the coal is changed over into power; it will require just $860 \mathrm{Kcal}$ of warmth to produce one unit of electricity. Because of different misfortunes, the warmth required to create one unit of power is high. Henceforth, around 2000 to $3000 \mathrm{Kcal}$ of warmth is required to produce one unit of electricity. $100 \%$ of warmth made in the hotter can't be captured. This is the essential reason causing low practicality for Thermal Generating Power Station. As such to keep up palatable warmth, more extent of coal is to be singed. One can keep up warmth by utilizing fitting nature of the bed Material. Without eating up more extent of coal, one can keep up bona fide temperature with the assistance of bed material. This bed material moreover asks us to diminish separating in evaporator tubes. With this establishment of appealing separator hardware, hotter ampleness can be reached out to $2.1 \%$ i.e., from $83.50 \%$ to $85.60 \%$ more, to keep up the typical temperature to keep up a key partition from kettle stoppages. An examination was coordinated to the different parameters to be viewed heading off to the establishment of an attractive separator. The different stages associated with the technique for establishment and a typical time for the establishment is merged in Fig.2.

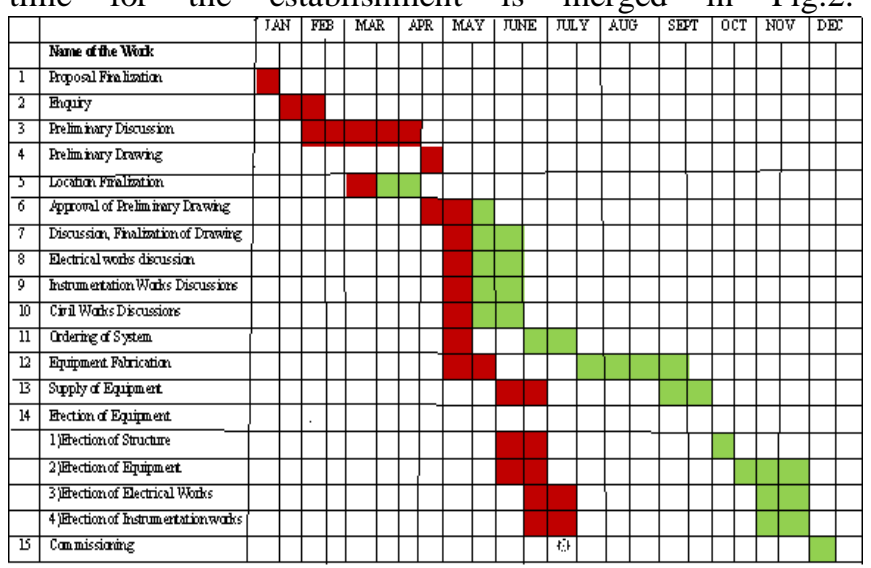

Fig.2: Proposed Planning of Magnetic Separator System

\section{Conclusions}

An endeavor has been made to perceive the use required to present attractive separator is around Rs. 23, 81,098.00and for 5840 Tons Bed material utilized, it has been discovered that the pay period is constrained to 20 months, 14 months and10 months if the magnetic components in the bed material is $5 \%, 7.5 \%$ and $10 \%$ solely. In addition for 6570 and 7300 Tons Bed material utilized, it has been discovered that the payroll interval is constrained to 18 months, a year and 9 months and 16 months, 11 months and 8 months if the magnetic component in the bed material is $5 \%, 7.5 \%$ and $10 \%$ respectively. Also an examination was guided as for the different parameters to be viewed setting off to the establishment of a magnetic separator. The different stages associated with the arrangement of establishment and an ordinary time for the establishment is 12 to 15 months. With the establishment of this Magnetic Separator, the boiler practically has been updated from $83.5 \%$ to $85.6 \%$ keeping up the required temperature consequently lessening the stoppages of the evaporator. The Proposed issue is tried with MATLAB condition and cost investigation of Thermal power plant is contrasted and existing writing information. The test outcomes demonstrate that the proposed technique furnishes achievable arrangement with critical funds and legitimate for ongoing tasks. At last the use of coal was diminished to 100 Tons for reliably and 36,500 Tons yearly. As such a $600 \mathrm{MW}$ Thermal Generating Power Station which uses CFBC Boiler can spare 36,500 Tons of coal for reliability. With the exhibited furthest reaches of

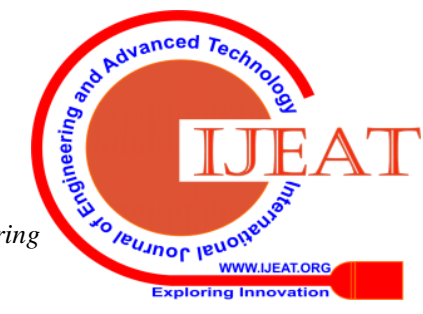


1, 31,240 MWs, the complete getting a decent arrangement on coal would connect with eight million tons and limiting the spoiling to an immense low measurement.

\section{REFERENCES}

1. Hong tian, Chen Yang, Xiao-long Gou, Yu-ying Zhang, Zheng-zhu Liao, "Experimental Study on CFBC Co-combustion of Municipal Solid Wastes and Oil Shale" Challenges of Power Engineering and Environment, Springer, PP: 1103-1108, 2017

2. K.M.Pandey and Ravindra Kumar "Numerical analysis of Coal Combustion in Circulating Fluidized Bed", International Journal of Chemical Engineering and Applications, Vol.2, No.6, December 2011.

3. Ankur B Vaidhya and AshwinBhabhor, "CFD Analysis of Bed Coil Tube using Advance CAE Tools and it's optimization of Erosion and Corrosion”, International Journal of Emerging Trends in Engineering and Development, ISSN: 2249-6149, Issue 3, Vol.2, My 2013.

4. Ravindra Kumar and K.M.Pandey "CFD analysis of Circulating Fluidized Combustion by department of Mechanical Engineering", IRACST Engineering Science and Technology: An International Journal (ESTIJ), ISSN: 2250-3498, Vol.2, No.1, 2012.

5. ThenmozilGanesn, Dr.siva Kumar Lingappan, “ A Survey on Circulating Fluidized Bed combustion boilers", International Journal of advanced Research in electrical, electronics and Instrumentation Engineering ( An ISO 3297:2007 Certified Organization) Vol.2, Issue.8, August 2013.

6. Ashish M. Pullekunnel, Manish R. Moroliy, "Optimization of Bed Material Consumption in a CFBC Boiler", International Journal of Engineering Research, Vol.4, Issue No.1, PP: 27-32, ISSN: 2319-6890(online), 2347-5013(print) 01 Jan 2015.

7. P.Potham Kumar Reddy, Raja sekhar and T. Nanda Kumar, "Study, Evolution, Design and Analysis of CFBC Boiler for usage of Biomass as a fuel", International Journal of Engineering, Development and Research, Volume 4, Issue 4.

\section{Authors Profile}

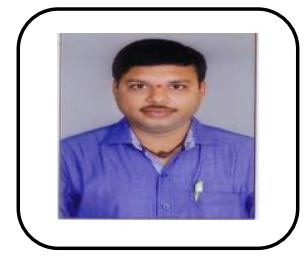

P V Narendra Kumar obtained his B.Tech (2004) from Sri Venkateswara University, Tirupati, A.P, India and M.Tech (2007) from Sri Venkateswara University, Tirupati, A.P, India. He is having a total teaching experience of 13 years He has published 6 papers in National/ International journals. . He is doing his Ph.D. in Sri Venkateswara University, Tirupati. Presently, he is working as Associate Professor in EEE of Priyadarshini College of Engineering and Technology, Nellore, A.P. His

research interest is Power System Operation \& Control, Fuzzy Logic and Artificial Neural Networks.

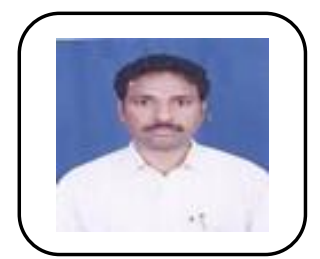

Ch. Chengaiah, obtained his B.Tech.(1999) from Sri Venkateswara University College of Engineering, Tirupati, A.P.. India and M.E (2000) from National Institute of Technology (NIT) formerly called as Regional Engineering College, Tiruchanupalli, Tamilnadu, India and Ph.D. (2013) from Sri Venkateswara University College of Engineering, Tirupati A.P. India. He is having a total teaching experience of 18 years. He has published 20 papers in National/ International journals. . At present 10 students are working for Ph.D. under his guidance. Presently, he is working as Professor in EEE of S.V.University College of Engineering, Tirupati, A.P., and India. His research interest is Power System Operation \& Control, Power Electronic Drives, Control Systems and Nonrenewable Energy Sources

G Kiran Kumar obtained his B.Tech and M.Tech from JNT University, AP, and India. He is having 10 Years of Industrial experience. Presently, He is working as Senior Engineer in Simhapuri Thermal Power Station, Andhra Pradesh, India. 